\title{
EFFECT OF PROCESSING CONDITIONS ON FORGEABILITY AND PROPERTIES OF HOT AND WARM-FORGED STEEL 300M
}

\begin{abstract}
Results of investigation of the effect of processing conditions of medium-carbon alloy steel AISI 300M on forgeability and microstructure-properties are presented here, including as-forged and heat treated condition of the material. The presented results concern two vital aspects of plastic forming of high-duty impression-die forgings, which underlay a selection of technological conditions which enable the accomplishment of the required quality of the forged part. These are: firstly, the microstructure and mechanical properties and their uniformity within a part and secondly, technological realization of forging the required geometry in the given processing conditions.

In order to define a favourable processing window, dynamic behaviour modeling in variable forging conditions was carried out, establishing a coefficient of energy dissipation $\eta \%$ and the metal flow instability areas, which indicated the temperature regime and strain rate range for the forging process. The constructed processing maps were subject to experimental verification in the die-forging tests, carried out on a screw press. Hot and warm forging conditions were applied accordingly to selected areas of the processing maps, representative for unique forging conditions occurring in the industrial practice.

Keywords: warm forging, processing maps, steel $300 \mathrm{M}$, forgeability, dynamic material modeling
\end{abstract}

\section{Introduction}

Steel $300 \mathrm{M}$ is an advanced grade of medium carbon ultrahigh strength steel referred to as ultra-high strength steel, whose composition, besides superior strength properties, is designed to amend for insufficient level of some operational characteristic, e.g. fracture toughness and/or cracking resistance. Owing to high strength, $300 \mathrm{M}$ steel is typically used in applications where superior strength properties are required, e.g. aircraft landing gears, airframe parts, fasteners, gears, transmission system components, pressure vessels etc [1,2].

Significant fraction of the applications are complex geometry parts, manufactured through forging techniques. Like other high strength steels, 300M is typically hot-forged [3]. Hot forging does not enable high accuracies to be achieved without coining, strengthening or calibration. Due to its chemistry, this steel is prone to decarburization while soaking at elevated temperatures. Therefore, machining was used after normalizing annealing to attain the final properties.

In many cases, accuracy and quality problems witnessed in hot forging can be reduced by the application of warm forging regime. As a rule, forging in lower working range is advantageous from the standpoint of net-forging accuracies, promoting material and machining savings, and due to other aspects such as preventing scale formation, excessive grain growth and decarburization to which grade $300 \mathrm{M}$ has a particular inclination [4]. However, successful use of warm forging is conditioned by two major aspects - i) forgeability, and ii) the final microstructure which in warm forging gain more importance. Both of these aspects can be taken into account in dynamic material modelling for the design of the forging process with use of processing maps, which combines macroscopic studies of flow stress dependence on the process conditions with microstructural response, referring to dynamic behaviour of deformed material and stability of plastic deformation [5-7]. The presented study concerns two vital aspects of plastic forming of high-duty impression-die forgings, which underlay selection of the technological conditions which enable accomplishment of the required quality of the forged part. These are: firstly, the microstructure and mechanical properties and their uniformity within a part, and secondly, technological realization of forging the required geometry in the given processing conditions.

\section{Experimental}

\subsection{Material characterization}

As-received steel $300 \mathrm{M}$ in the form of a hot-rolled bar was used in the study. The chemical composition of the grade used in the study is presented in Tab. 1. The experiment was preceded

\footnotetext{
AGH UNIVERSITY OF SCIENCE AND TECHNOLOGY IN CRACOW, DEPARTMENT OF METALS ENGINEERING AND INDUSTRIAL COMPUTERS SCIENCE, AL. MICKIEWICZA 30, 30-059 KRAKÓW, POLAND

Corresponding author: pskubisz@metal.agh.edu.pl
} 
by as-received metallographic characterization and dilatometric examination in order to estimate initial microstructure and characteristic points of transformation, which were used for definition of forging temperatures. As indicated in volumetric heat expansion tests carried out for the same heat [8], austenite formation began at $770^{\circ} \mathrm{C}\left(A_{c 1}\right)$, and ferrite-austenite transformation completed in $850^{\circ} \mathrm{C}\left(A_{c 3}\right)$. The initial microstructure (as shown in Fig. 1) in as-received condition consisted of bainite-martensite mixture with fine particles identified as cementite (Fig. 1c).

TABLE 1

Chemical composition of steel $300 \mathrm{M}$ used in the study

\begin{tabular}{|c|c|c|c|c|c|c|c|c|c|c|}
\hline \hline $\begin{array}{c}\text { Alloying } \\
\text { element }\end{array}$ & $\mathbf{C}$ & $\mathbf{M n}$ & $\mathbf{S i}$ & $\mathbf{C r}$ & $\mathbf{M o}$ & $\mathbf{N i}$ & $\mathbf{S}$ & $\mathbf{P}$ & $\mathbf{V}$ & $\mathbf{F e}$ \\
\hline $\begin{array}{c}\text { Content, } \\
\text { wg. \% }\end{array}$ & 0,38 & 0,6 & 1,45 & 0,7 & 0,29 & 1,65 & 0,01 & 0,01 & 0,05 & bal. \\
\hline
\end{tabular}

\subsection{Flow behaviour analysis}

Flow curves were elaborated for the needs of description of the rheological behaviour of steel $300 \mathrm{M}$ in numerical modeling with finite element method (FEM) and construction of the processing maps. The flow curves (set together on graphs in Fig. 2.) were derived from compression tests conducted on testing machine Gleeble 3800. FEM modeling of the upset forging process was carried out with code QForm3D with assumption of rigid-plastic model of deformed body and Levanov friction model, applying coupled thermal-mechanical analysis for solution of actual temperature, strain and stresses fields in the points of interest.

\subsection{Dynamic behaviour modeling}

Hot deformation characteristics were established based on uniaxial compression tests. Compression tests were carried out in a wide range of temperatures $\left(800-1200^{\circ} \mathrm{C}\right)$ and strain rates (0,01-100 $\left.\mathrm{s}^{-1}\right)$. Obtained stress-strain curves were a basis for correlation between Zener-Hollomon parameter and flow stress, for which the constitutive equation proposed by Sellars was used. Having estimatied of activation energy $\left(Q_{\dot{s} r}=\mathrm{kJ} \cdot \mathrm{mol}^{-1}\right)$, coefficient of energy dissipation $\eta \%$ and processing maps were constructed. The maps indicated four windows of the metal flow instability. As an experimental verification of the theoretical analysis of the flow behaviour, experimental tests
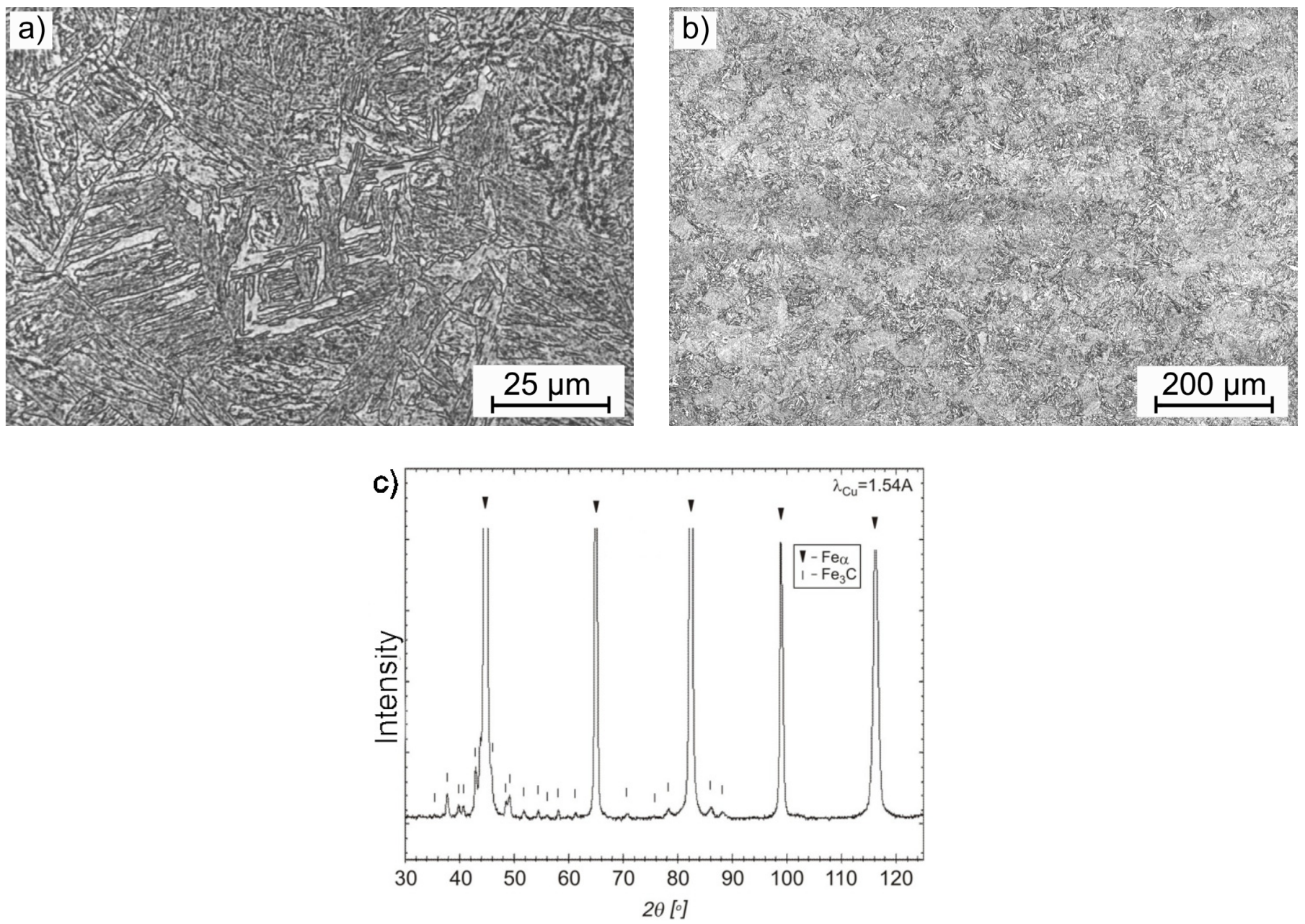

Fig. 1. Characterization of the material used in the study: a-b) microstructure in as-received condition, c) identification of the precipitates with $\mathrm{x}$-ray diffraction 

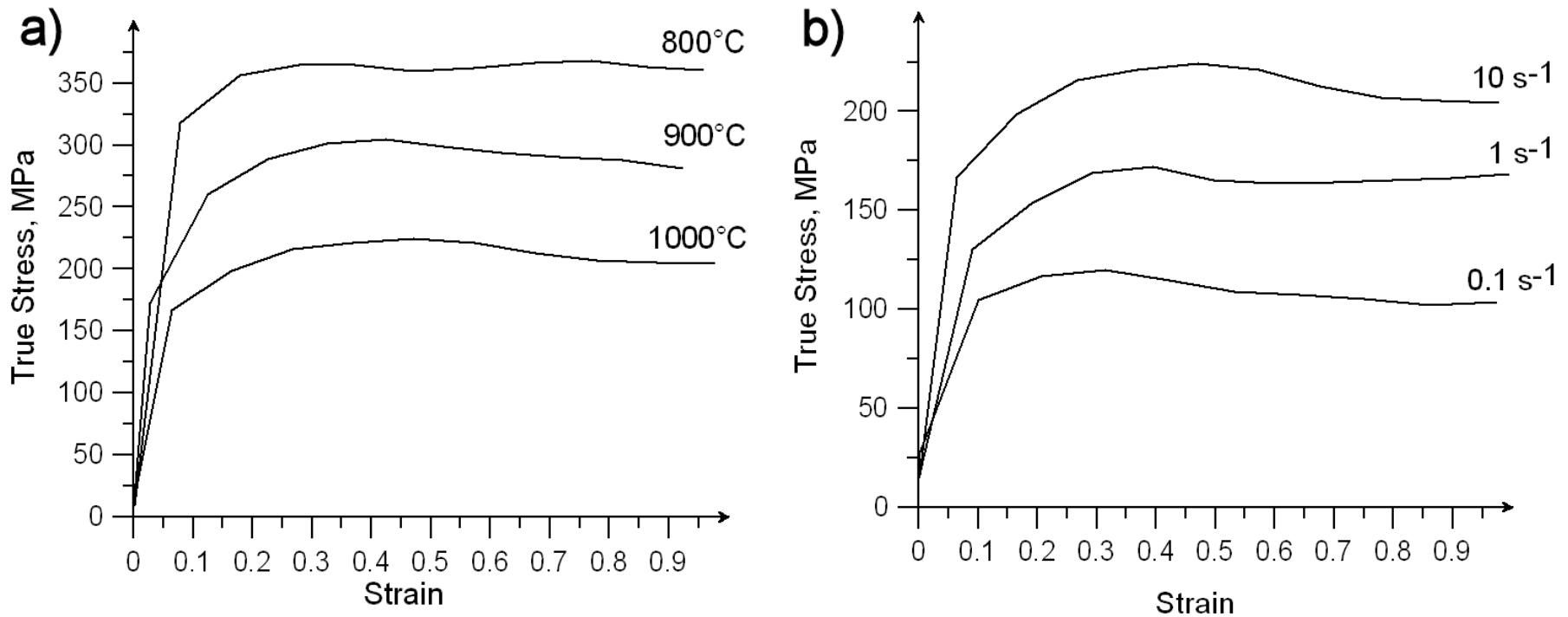

Fig. 2. Stress-strain characteristics derived from uni-axial compression tests on Gleeble 3800 for: a) constant strain rate 10 1/s, b) constant temperature $1100^{\circ} \mathrm{C}$

were conducted with screw press and hammer forging in lower temperature range of the work regime, $800-850^{\circ} \mathrm{C}$. Obtained samples exhibited metallurgical soundness, however, indicated nonuniformity of deformation reflected by variations microstructure resultant from selective deformation and inhomogeneous pattern of recrystallized grains. As suggested by the calculated processing windows, increasing the work temperature resulted in improvement in microstructure uniformity, reflected by mechanical properties in as-forged condition.

Workability analysis carried out for selection of the most favourable forging conditions for steel $300 \mathrm{M}$ was based on Dynamic Material Modelling method [5-7,9,10] with the use of Prasad approach [5,6,11-13]. In the Dynamic Material Model (DMM) the unit power $(P)$ absorbed - by the material during plastic working is expressed in the following way $[5-7,9,10]$ :

$$
P=\sigma+\dot{\varepsilon}=G+J=\int_{0}^{\dot{\varepsilon}} \sigma_{p} d \dot{\varepsilon}+\int_{0}^{\sigma} \dot{\varepsilon} d \sigma
$$

where $G$-dissipator content (represents the power dissipated by plastic work, which is converted into heat), $J$-dissipator cocontent, a component which represents power dissipation into microstructural transformations, such as dynamic recrystallization, dynamic recovery and/or grain growth. The value of this component can be calculated from the formula:

$$
J=\int_{0}^{\sigma} \dot{\varepsilon} d \sigma=\frac{\sigma+\dot{\varepsilon}+m}{m+1}
$$

where: $\varepsilon$ constant true strain value, $\sigma-$ the flow stress, MPa, $\dot{\varepsilon}$ the strain rate, $\mathrm{s}^{-1}, m$ parameter of the strain rate sensitivity of flow stress, usually referred to as

$$
m=\left(\frac{\partial \log \sigma}{\partial \log \dot{\varepsilon}}\right)_{T, \varepsilon}
$$

The efficiency of power dissipation $(\eta)$, as a measure of the ability to undergo plastic deformation, was estimated from the equation proposed by Prasad

$$
\eta=\frac{J}{J_{\max }}=\frac{2 m}{m+1}
$$

where $J$ : dissipator co-content $J=J_{\max }=\frac{P}{2}=\frac{\sigma \dot{\varepsilon}}{2},-$ or $m=1$, $m$ - coefficient describing sensitivity to strain rate $[5,6]$. With the use of calculated value of $\eta(\%)$, maps of dissipation power efficiency were built. The criterion for identification of the metal flow instability during hot deformation put forward by Ziegler [14] is

$$
\xi(\dot{\varepsilon})=\frac{\partial \log \left(\frac{m}{m+1}\right)}{\partial \log \dot{\varepsilon}}+m
$$

With the assumption that the parameter $\xi \leq 0$ is reached, microstructural instability of the metal flow is concluded, reflected by occurrence of e.g. adiabatic shearing bands, straininduced dynamic ageing, flow turbulences. Process instability is a complex notion referring to a given temperature and strain rate, which can be referred to as the conditions under which the deformation takes place. Parameter $\xi$ forms a sort of warning while designing the process for a new material, whereas any changes in the value of the parameter enable the construction of an instability map.

The processing $\mathrm{mp}$ is made up by superposition of power dissipation effectiveness map ( $\eta(\%)$ elucidated with isoclines) with the metal flow instability parameter $(\xi))$.

\subsection{Forging test conditions}

Physical verification was carried out by means of physical modelling. The experimental results were to confirm the applicability of the processing maps in design of the forging process in aspects of producing sound part and proper microstructure, 
which is indirectly indicated by instability and energy dissipation parameters, respectively. For assessment of final properties of the as-forged steel $300 \mathrm{M}$ microstructure was analysed and tensile properties established.

The forging tests were conducted with screw press and hammer forging in hot forging $\left(1000^{\circ} \mathrm{C}\right)$ and within the range of the warm work temperature range, $800-850^{\circ} \mathrm{C}$.

The rolled bar was cut on sections of length resultant from the volume the forged part including flash and subject to homogenization annealing in accordance with temperature regime common for that grade [3] and heated up/cooled down to forge temperature. Deformation took place after soaking at the deformation temperature for 20 minutes. Forging experiment was carried out on a screw press of maximum flywheel energy $16 \mathrm{~kJ}$ and ram starting speed $0.7 \mathrm{~m} / \mathrm{s}$. Based on dilatometric curves characterized for this heat [8] transformation points were determined, which allowed selection of forging temperatures. Three different deformation temperatures were used, so as to represent three unique temperature ranges: 1) $1000^{\circ} \mathrm{C}$ - hot-work range, 2) $850^{\circ} \mathrm{C}$ - lower range of hot-forging regime, and 3) $800^{\circ} \mathrm{C}-$ intercritical range between $A_{c 3}$ and $A_{c 1}$, as shown in Fig. 3a).

Pyrometer measurement was maintained for tracing the actual forging temperature and calibrated with established emissivity characteristics to ensure accuracy [15] as well as thermocouple measurement during soaking, forging and cooling, with probe located in the core of the billet at the half of the height. From the forged samples (Fig. 3b) specimens for metallographic work and tensile testing were extracted, in direction suggested by ultrasonic detection so as to omit post-probe discontinuities.

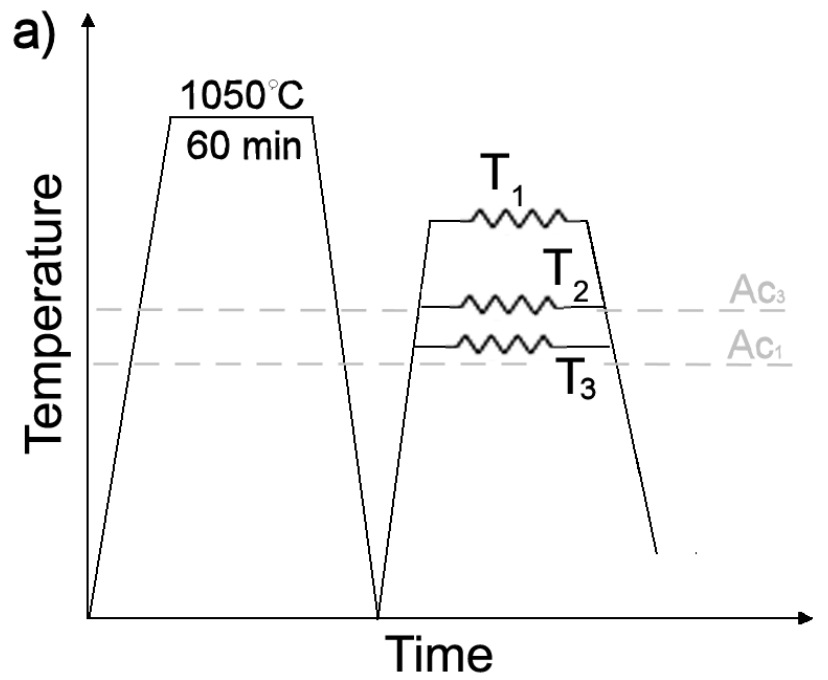

b)

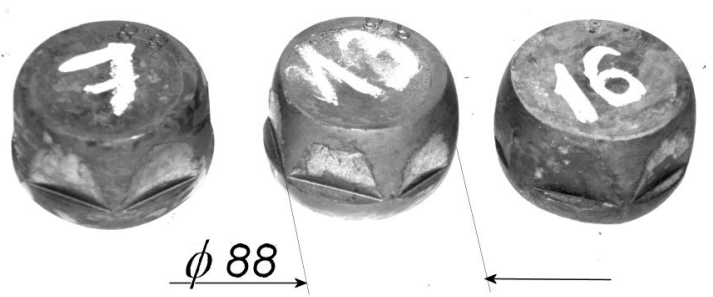

Fig. 3. The experimental specimens: a) plan of the tests, b) the forged samples

\section{Results}

\subsection{Workability estimation with processing maps}

In assessment of warm-range forgeability of steel $300 \mathrm{M}$, significant sensitivity of the power dissipation and stability of deformation in temperature $800 \div 900^{\circ} \mathrm{C}$ can be concluded. It means that there is a linear relation between instant values of the strain rate hardening exponent and temperature increment.

The processing maps constructed for the Cr-Mo steel 300M (Fig. 4) indicate the areas of metal flow instability (dark fields), for which $\xi \leq 0$, and elucidated with isoclines levels of power dissipation, $\eta \%$. For the considered range of strain $\varepsilon=0.1,0.3$, $0.5,0.7$ and 0.9 equivalent domains (processing windows of strain rate promoting highest efficiency of plastic deformation at temperature concerned) can be determined. They are the basis for definition of suggested values of these parameter for forging process, which for warm forging ranges between $\dot{\varepsilon}=1 \div 10 \mathrm{~s}^{-1}$ and for hot forging $\dot{\varepsilon}=0.03 \div 1 \mathrm{~s}^{-1}$, providing driving force for dynamic recovery and recrystallization with satisfactory stability of the deformation process, without local energy accumulation. According to thus constructed maps, proper stability of the forging process conditions is expected within $825 \div 900^{\circ} \mathrm{C}$ and $1000 \div 1170^{\circ} \mathrm{C}$. For strain degree 0.9 two processing windows can be distinguished: rectangular field featuring efficiency $\eta=19-24 \%$ for temperature $825 \div 900^{\circ} \mathrm{C}$ and strain rate ranging $1 \div 10 \mathrm{~s}^{-1}$. The available window corresponds to forging small or flat geometries on screw or hydraulic press.

Isoclines of parameter $\eta \%$ attain density and gradient conforming to increasing temperature, and their contours suggest uniformity and the metal flow stability during forging stages.

The other processing window found for temperatures $1000 \div 1170^{\circ} \mathrm{C}$ and strain rate $0.03 \div 1 \mathrm{~s}^{-1}$ is contained in the range of isoclines efficiency $\eta=22-32 \%$. The isoclines of the power dissipation parameter feature a slight increments from eachother occasionally bulging towards higher speeds at $1000 \div 1100^{\circ} \mathrm{C}$ switching to higher density within $1100 \div 1170^{\circ} \mathrm{C}$. It may mean that the plastic flow resistance is function of $\varepsilon, \dot{\varepsilon}, T$, and the behaviour is representative of the response of the material hot forged on slow action hydraulic presses.

When reaching 0.9 two areas of flow instability can be found. The first one is located within the range $800-825^{\circ} \mathrm{C}$ above the strain rate of $56 \mathrm{~s}^{-1}$. Adiabatic shear bands and/or microstructural defects may occur in that area. The coordinates of the other one are $800 \div 875^{\circ} \mathrm{C}$ and $0.01-0.25 \mathrm{~s}^{-1}$. As far as the intermediate amount of strain, $\varepsilon=0.1-0.7$ is concerned, the areas extend and move towards lower Zener-Hollomon values.

\subsection{Properties of the forged samples}

Hot forged specimens after air cooling produced typical microstructure for both of the analysed regions. Beneath $40 \mu \mathrm{m}$ deoxitated case of ferrite, the undersurface regions grade $300 \mathrm{M}$ exhibits martensitic-bainitic structure with the laths reaching 
a)
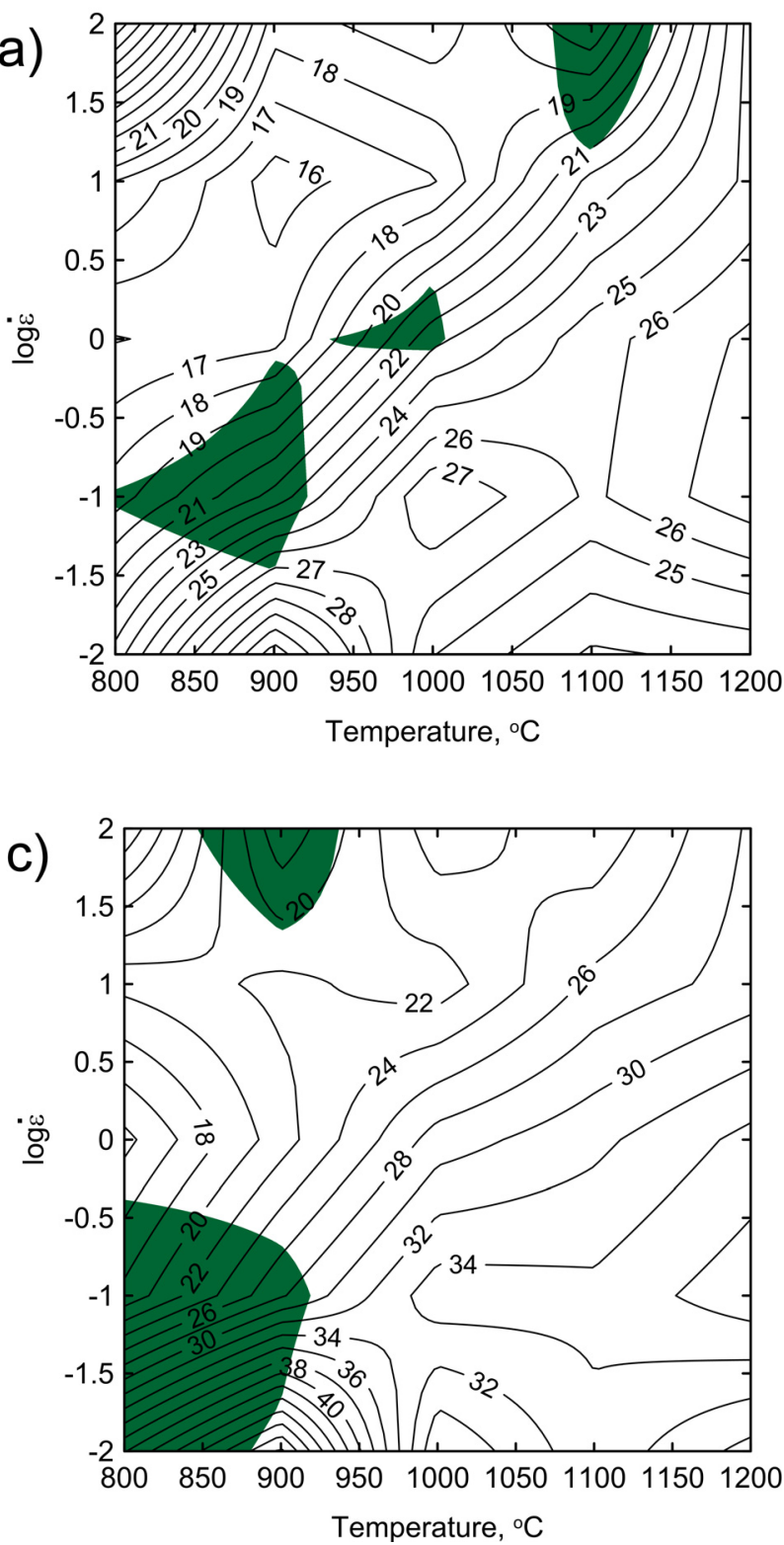

e)

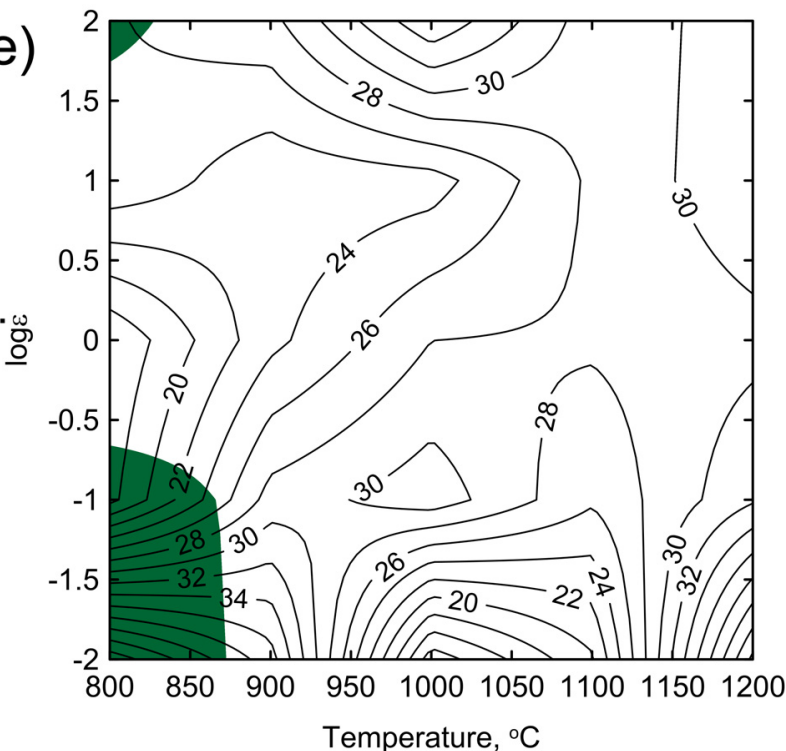

b)
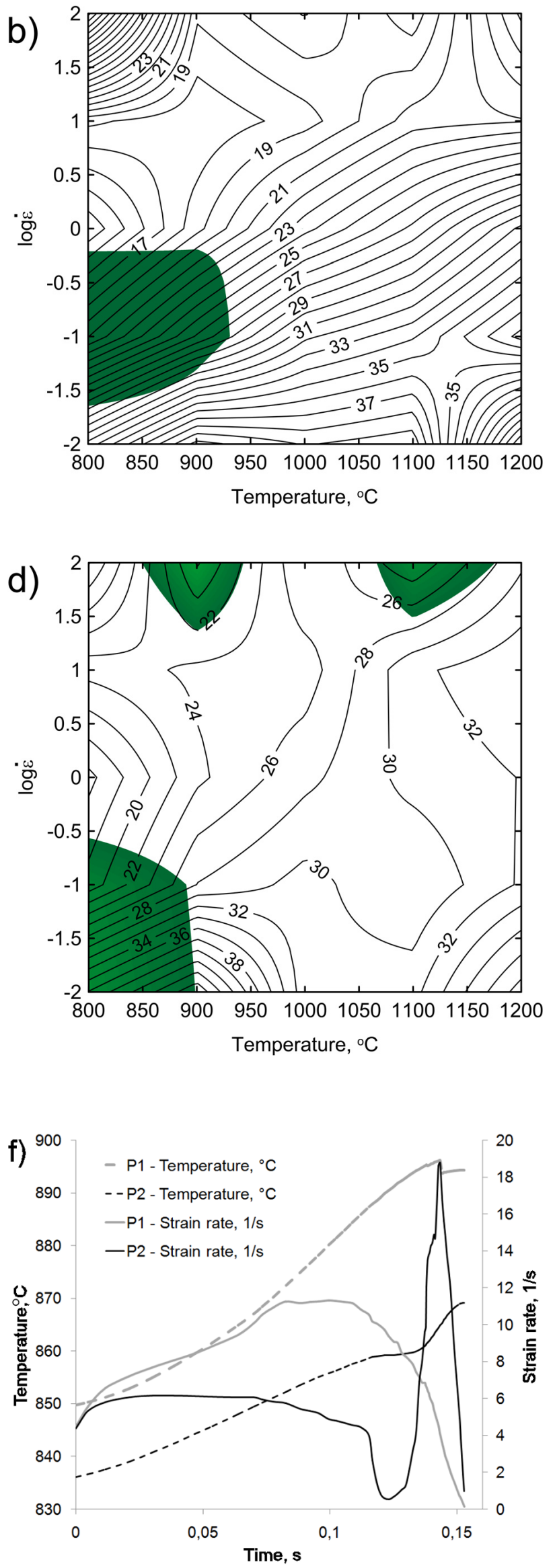

Fig. 4. Processing maps in function of temperature and strain rate with consideration of instability areas constructed for steel $300 \mathrm{M}$ with Prasad approach for true strain: a) 0.1, b) 0.3 , c) 0.5 , d) 0.7 , e) 0.9 
$12 \mu \mathrm{m}$ in length, which come down to average 6-7 $\mu \mathrm{m}$ in the bulk. In the warm forged specimens, the grains are outlined with proeutectoid ferrite which at lower temperature appears mixed with pearlitic and/or bainitic colonies and features subgrain formation in the ferrite phase. In the interior of the bulk specimens the microstructure consists of pearlitic-ferritic microstructure of recrystallized grains of 9 ASTM grain size (Fig. 5b).

It is obvious that the phase composition is related to hardenability and location concerned, whereas the grain structure can tell more about dynamic behaviour. In both cases the grain structure is similar, although no distinct flow localization was observed, the grain size was not uniformly distributed, in the (Fig. 5b,c,e,f) areas of 9 ASTM in vicinity of 6-7 ASTM can be seen. This tendency is more distinct in the intermediate forging regime, where preferential flow localization in the unstable region of austenitic transformation took place in the aftermath of heat generation. In the both forging ranges, hot and warm, the forged material indicated relatively similar flow behaviour, resulting in sound forgings, wherein no separation or cracking occurred. In many studies concerning workability assessment with processing maps, the microstructure is quenched practiced so as to freeze the as-forged condition. In this work the idea was
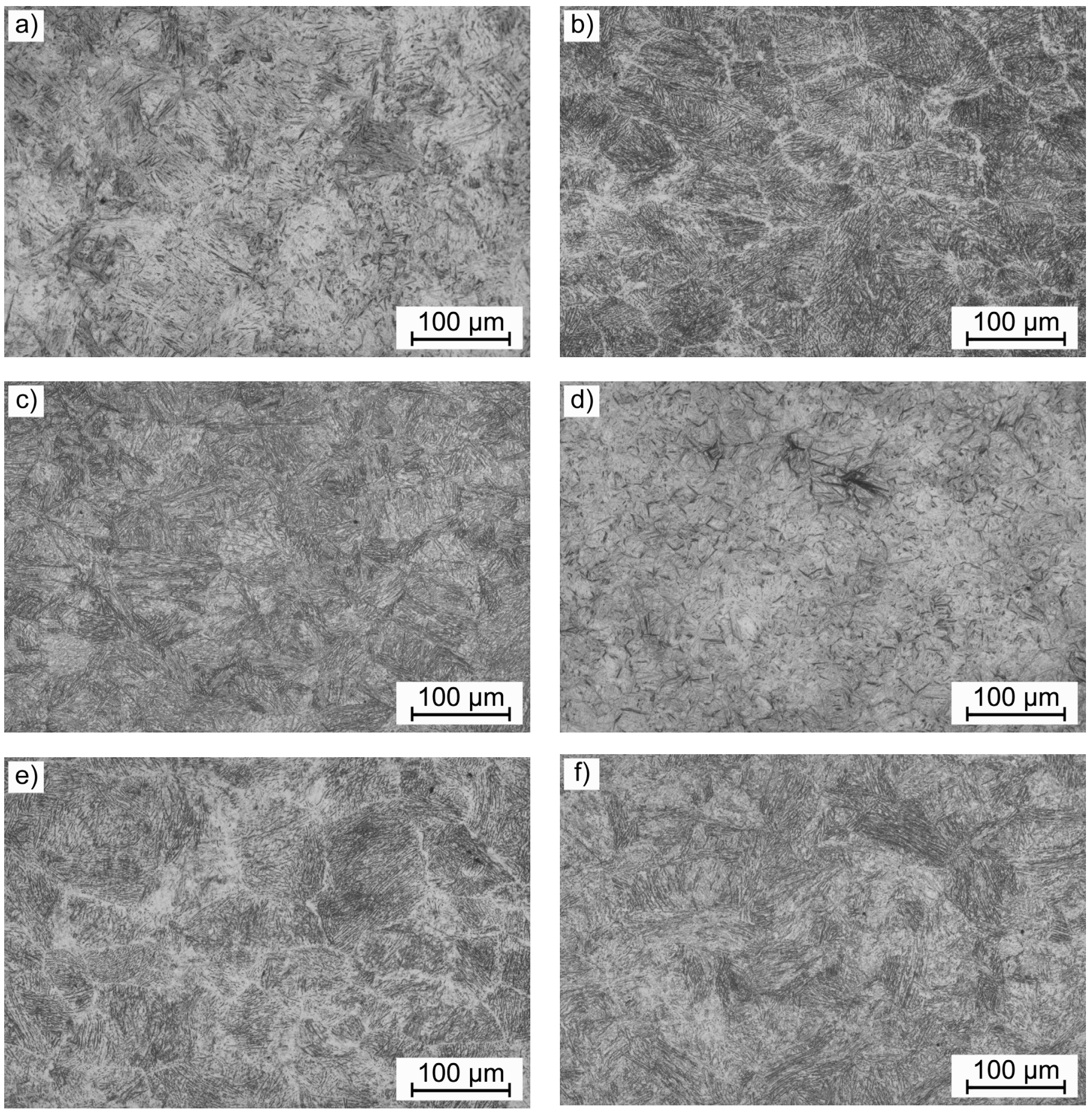

Fig. 5. Microstructure of analysed steel $300 \mathrm{M}$ forged at: a), d) $800^{\circ} \mathrm{C}$; b), e) $850^{\circ} \mathrm{C}$ and c), f) $1000^{\circ} \mathrm{C}$ in the undersurface region (a-c) and in the axis (d-f) 
to reflect the material behaviour in a state typical of air-cooled condition, representative of good hardenability steels. Thus the workability and microstructure evolution can be evaluated through the obtained mechanical properties, shown in Table 2. From the mechanical properties and microstructure one can conclude the workability was satisfactory in the light of providing amount of deformation required for high strength and fair ductility, typical of quenched condition, in reference to related studies $[16,17]$. The microstructure is even throughout the cross-section and the final features depend rather on the cooling conditions and related to amount of martensite and rest austenite, uniformity of strength properties can be assumed from the standpoint of former austenite grain size after forging [18].

TABLE 2

Tensile properties of steel 300M in as-forged condition

\begin{tabular}{|c|c|c|c|c|c|c|}
\hline \hline $\begin{array}{c}\text { Forging, } \\
\text { tempera- } \\
\text { ture, }\left[{ }^{\circ} \mathbf{C} \text { ] }\right.\end{array}$ & $\begin{array}{c}\text { TYS, } \\
\text { MPa }\end{array}$ & $\begin{array}{c}\text { UTS, } \\
\text { MPa }\end{array}$ & $\begin{array}{c}\text { Elon- } \\
\text { gation, } \\
\mathbf{\%}\end{array}$ & $\begin{array}{c}\text { Area re- } \\
\text { duction, } \\
\mathbf{\%}\end{array}$ & $\begin{array}{c}\text { V-notch } \\
\text { Impact } \\
\text { strength, } \\
\mathbf{J}_{\mathbf{c m}} \mathbf{2}^{2}\end{array}$ & $\begin{array}{c}\text { Hardness } \\
\text { HRC }\end{array}$ \\
\hline 1000 & 1505 & 2231 & 5,8 & 22 & 43,3 & 57 \\
\hline 850 & 1143 & 1885 & 6,6 & 21 & 34,0 & 55 \\
\hline 800 & 855 & 1634 & 7,8 & 12 & 33,2 & 53 \\
\hline
\end{tabular}

Numerically estimated values of strain and strain rate (Fig. $5 \mathrm{f}$ - grey line) observed in the axis are linked with maps in (Fig. 5c-d). The processing window locates between two instability areas. From the standpoint of workability that provides are relatively safe processing conditions, however, there is a local minimum of energy dissipation found for strain rate ranging from $10^{0}$ to $10^{1} \mathrm{~s}^{-1}$, which means that under these conditions the material is at closest to viscosity. Bigger failure hazard could be expected in the location which lies in the near-surface region of hexagonal face (Point 2 - black line in Fig. 5f), where strain rate reaches double values or in the flash area, where it grows up to $90 \mathrm{~s}^{-1}$. However, the high strain stage of forging was preceded by considerable deformation at moderate strain rate, enhancing plasticity. The corresponding region on high-strain processing maps (Fig. 5d-e) is closer to the "upper" instability area, which here is shifted to lower temperature range and the area of low energy dissipation forms a wedge reaching $1000^{\circ} \mathrm{C}$. Yet the hot forging was still beyond this area, resulting in austenite grain size comparable to those observed in the bulk.

Confronting the resulted microstructure and properties with processing maps, it can be said the material demonstrates relatively good forgeability, irrespective of the temperature regime. Comparing the material condition between analysed locations (Fig. 5a-c) versus (Fig. 5d-f), much lesser difference is observed than could be expected from the values of strain and strain-rate concentration in the axis of the specimens (Point 1 in Fig. 4f) and the microstructure in the surface (Point 2 in Fig. 4f) and, respectively, isoclines at corresponding strains. The surface of the specimens was good, without signs of separation or rupture. One may conclude that the workability of steel $300 \mathrm{M}$ at lower hot forging temperature and in intercritical region is relatively good. As indicated in strain rate and temperature plots derived from numerical simulation, screw press, similarly to mechanical press, offers rates of straining which locate just between two instability regions which may be ascribed to hammers on one side and hydraulic presses on the opposite, where a large instability region persists from small to large strain levels. In addition to increased strain rates, the area is omitted due to increasing actual temperature by deformation heat generation.

\section{Conclusions}

The presented study allowed the analysis of the flow behaviour of ultra-high strength steel 300M with use of dynamic material modelling and elaboration of processing maps. The main conclusions it allowed to formulate are:

1. Definition of sensitive areas of energy dissipation into solid state dynamic transformations and regions of metal flow instability during forging indicated ,safe" forging regime of temperature and selection of equipment for realization in selected temperature range. In this respect screw and mechanical presses provide suitable strain rate for average upset-forged geometry.

2. Workability indices defined by instability coefficient and energy dissipation coefficient in the function of strain rate versus working temperature suggest relatively good workability of the material both in hot and warm forging temperature. The processing window in which observed strain rates, $20 \div 90 \mathrm{~s}^{-1}$ are found, exhibits maximum viscosity up to $1000^{\circ} \mathrm{C}$ temperature, which means the least energy is dissipated into dynamic phenomena which could contribute to the metal flow instability. Thus, warm forging regime offers good technological conditions for forging on a fast action press, preventing from detrimental surface effects, such as excessive scale formation or decarbonization.

\section{Acknowledgements}

Financial assistance of MNiSzW within the statutory funds in the framework of agreement 11.11.110.292 is acknowledged.

Special thanks are expressed to Krzysztof Kłaput of forge plant Śrubena Unia S.A. for facilitating the industrial forging equipment and to Tadeusz Skowronek, Piotr Bała, Marek Paćko and Joanna Kowalska for assistance in material characterization.

\section{REFERENCES}

[1] T.E. Pistochini, M.R. Hill, 34, 521-533 (2011).

[2] T.J. McCaffrey, ASM Handbook 01, Properties and Selection: Irons, Steels, and High-Performance Alloys. ASM International, Materials Park,Ohio, 1990.

[3] S.L.Semiatin, ASM Handbook 14, Forging and Forming, ASM International, 1996. 
[4] J. Luo, M.Q. Li, Y.G. Liu, H.M. Sun, Materials Science \& Engineering A 534, 314-322 (2012).

[5] Y.V.R.K. Prasad, S.Sasidhara (ed.), Hot working guide: A compendium of processing maps, ASM International, 1997.

[6] G.E. Dieter, H.A.Kuhn, S.L. Semiatin, Handbook of Workability and Process Design, ASM International, 2003.

[7] N.S.V.S. Murty, N.B. Rao, B.P. Kashyap, Journal of Materials Processing Technology 166, 268-278 (2005).

[8] S. Bednarek, J. Krawczyk, P. Bała, A. Łukaszek-Sołek, in J. Kusiak, J. Majta, D. Szeliga (Eds.),Weinheim: Wiley-VCH VerlagGmbH\&Co. KGaA, cop. 2012, Steel Research International; spec. ed., 179-182.

[9] Y.V.R.K. Prasad, T. Seshacharyulu, International Materials Reviews 43, 243-258 (1998).

[10] Y.V.R.K. Prasad, Journal of Materials Engineering and Performance 12, 638-644 (2003).
[11] A. Łukaszek-Sołek, Acta Metallurgica Sinica (English Letters) 28, 122-131 (2015).

[12] A. Łukaszek-Sołek, J. Krawczyk, Materials and Design 65, 165173 (2015).

[13] A. Łukaszek-Sołek, P. Skubisz, Polska Metalurgia w latach 20112014, Komitet Metalurgii PAN 669-683 (2014).

[14] E. Pu, W. Zheng, J. Xiang, Z. Song, J. Li, Materials Science and Engineering A 598, 174-182 (2014).

[15] P. Skubisz, P.Micek, J. Sińczak, M. Tumidajewicz, Solid State Phenomena 177, 76-83 (2011).

[16] Y. Tomita, Materials Science and Technology 11, 335-339 (1995).

[17] R. Zhao, T. Liu, X. Zhao, Materials Science Forum 749, 287-293 (2013).

[18] P. Skubisz, Ł. Lisiecki, Key Engineering Materials 611-612, 167172 (2014). 